\title{
A IMAGEM DO "JARDIM DE ADÔNIS" E A REFLEXÃO SOBRE A ESCRITA COMO PARADIGMA PARA DETERMINAÇÃO DO LÓGOS NO FEDRO DE PLATÃO (276B1-277B3)*
}

\section{THE IMAGE OF THE “GARDENS OF ADONIS” AND THE REFLECTION ON WRITING AS A PARADIGM FOR DETERMINING THE LÓGOS IN PLATO'S PHAEDRUS (276B1-277B3)}

Fábio Fortes https://orcid.org/0000-0003-4411-7115 fabio.fortes@ufjf.edu.br Universidade Federal de Juiz de Fora, Brasil

\begin{abstract}
RESUMO O trecho entre $276 b 1$ e $277 b 3$ do diálogo Fedro tem sido usado como indicio de uma dicotomia entre oralidade e escrita, que seria, por sua vez, signo de uma inconciliável relação entre a dialética e a escrita. Ambas são associadas, respectivamente, a uma atividade séria (spoudé) e a uma brincadeira ou jogo (paidiá). Em nossa leitura, pretendemos mostrar não ser possivel subscrever tal associação, tendo em vista que, por um lado, a passagem deve ser lida como uma espécie de síntese de uma reflexão mais abrangente
\end{abstract}

* Artigo submetido em 03/06/2020. Aprovado em 02/03/2021.

KRITERION, Belo Horizonte, n 150, Dez./2021, p. 705-722 
(a determinação do lógos filosófico, i.e., a dialética) e, por outro, que nela se entreveem camadas de significação produzidas pelo diálogo intertextual (o debate sobre a escrita encetado entre Alcidamante e Isócrates). Nesse sentido, propomos uma interpretação que leva em conta uma análise imanente da passagem, mostrando que ela carece dos significantes para uma dicotomia oralidade vs. escrita, seguida de uma reflexão que a repõe no enquadre do diálogo, ao analisarmos os sentidos filosóficos da imagem do "Jardim de Adônis" e da oposição entre paidiá e spoudé.

Palavras-chave Platão. Escrita. Oralidade. Dialética. Lógos.

ABSTRACT The passage between $276 b 1$ and $277 b 3$ of the dialogue Phaedrus has been used to indicate a dichotomy between orality and writing as a sign of an irreconcilable relationship between dialectics and writing. Both of them are associated respectively to a serious activity (spoudé) and a game (paidiá). In our reading, we intend to show that it is not possible to subscribe to such association, considering, on the one hand, that the passage must be read as a kind of synthesis of a more comprehensive reflection (the determination of the philosophical lógos, i.e., dialectics) and, on the other hand, that it is possible to see in this context layers of meaning produced by an intertextual dialogue (the debate on writing between Alcidamas and Isocrate). In this sense, we propose an interpretation which takes into account an immanent analysis of the passage, showing that it does not display signifiers for subscribing the dichotomy between orality and writing, followed by a discussion that puts it back in the overall context of the dialogue, by analysing the philosophical meaning of the image of the "Gardens of Adonis" and the opposition between paidiá and spoudé.

Keywords Plato. Writing. Orality. Dialetics. Lógos.

\section{Introdução}

A passagem entre $276 \mathrm{~b} 1$ e $277 \mathrm{~b} 3$ do Fedro consigna a célebre imagem do "Jardim de Adônis", pela qual Platão reflete sobre qual deveria ser a atitude do filósofo diante dos discursos (e da escrita). O filósofo - dispondo

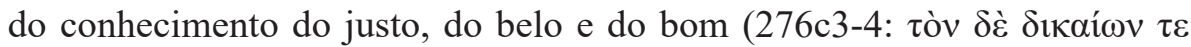

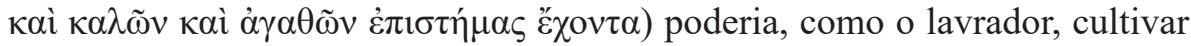
"jardins das letras" por mero divertimento (276d2: $\pi \alpha 1 \delta 1 \tilde{\alpha} \varsigma \chi \alpha$ á disso, esse divertimento pudesse ter a vantagem de amealhar um "tesouro de 
lembretes" (273d3: vं valer em sua prática filosófica? Na tentativa de responder a essas questões, que decorrem dessa passagem, muitos argumentos foram evocados em defesa de um possível divórcio entre a dialética e a escrita. Com efeito, a imagem que a passagem contém serviu de matéria para que se associasse o cultivo do "Jardim de Adônis" à prática da escrita da filosofia - tomada apenas como um jogo ou uma brincadeira sem maior importância ( $\pi \alpha 1 \delta 1 \alpha$ ) - opondo-a à dialética, que seria, por sua vez, uma atividade séria ( $\sigma \pi 0 v \delta \grave{)}$ e oral, como vemos no comentário de T. Szlézak (2009) e de muitos dos estudiosos da assim chamada "Escola de Tübingen-Milão" (como Reale, 2004 [1991]; Hösle, 2008; e Perine, 2014).

Ainda que nos pareça haver na passagem uma certa distinção entre a dialética e a produção de discursos, materializada pela distinção entre uma atividade bela, mas não necessariamente filosófica - como o cultivo dos Jardins

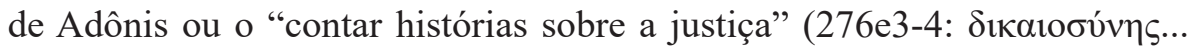

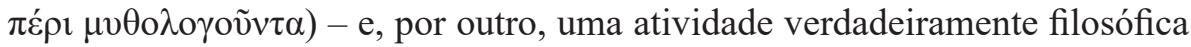
- a prática da lavoura e da dialética -, neste artigo pretendemos desfazer a associação entre oralidade e dialética, propondo uma leitura dessa importante passagem do Fedro na qual oferecemos, como consequência, uma interpretação filosófica da oposição "jogo" vs. "atividade séria", que passa ao largo da simplificação que, a nosso ver, consiste na leitura que opõe oralidade e escrita. Neste trabalho, seguimos a edição de H. Yunis (2014), tendo como referência a tradução de M. C. Reis (2016).

\section{Oralidade vs. escrita?}

Na passagem entre 276b1 e 277b3, Sócrates inicia uma discussão sobre a escrita na sequência da narrativa do "mito de Theuth" (274c5-275b2)1. A escrita, a partir dessa conhecidíssima passagem, é tomada como signo de uma discussão mais ampla em torno dos discursos, tema que percorre todo o $\mathrm{Fedro}^{2}$.

1 Não é nosso objetivo nesse artigo apresentar uma análise específica dessa passagem, menos ainda de demonstrar como também nela não se sustenta uma condenação filosófica da escrita, ademais já muito bem demonstrado por Trabattoni, que recupera essa fecunda discussão (Trabattoni, 1993; 2003). Nesse sentido, apenas gostaria de dizer que, no mito em questão, temos ao menos contrapostas duas posições - uma favorável à escrita, do seu inventor, Theuth, e uma contrária à escrita, à do rei egípcio, Thamos. Embora se possa talvez admitir, na fala de Sócrates, nessa passagem específica, um apoio à posição do rei egípcio, como veremos adiante, isso não implica necessariamente a posição de Platão, do que dependeria uma associação imediata entre Platão e seu personagem Sócrates, à revelia da rica polifonia que emerge do diálogo como um todo.

2 Conforme demonstramos em nossa tese, o tema das letras é apresentado como um paradigma para pensar o filosofar (o pensamento dialético), capturando, no campo da linguagem, a mesma ambiguidade consignada 
É por essa razão que se consignam nesse trecho referências ao "escrever", aqui associado a uma das formas do lógos, como se pode atestar pelo emprego de um léxico específico nesse sentido:

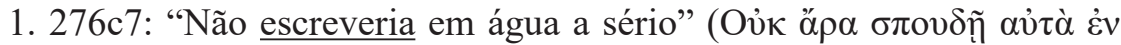

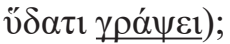

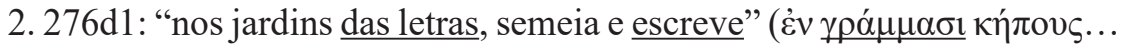

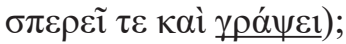

3. 276d2-3: "escreve formando para si um tesouro de lembretes" ( $\gamma \rho \alpha ́ \varphi \eta$

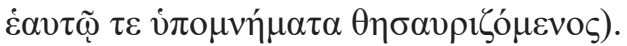

Vemos nessas passagens a associação da prática dos discursos à escrita, nelas não havendo contudo uma contraposição explícita com o modo oral do discurso. Essa mesma prática de escrita, inicialmente associada ao grapheîn, é referida logo à frente como um mythologeîn, isto é, um "contar histórias", termo que, se não remete exclusivamente a uma prática oral, ao menos admite a oralidade como seu traço semântico mais comum: "[a prática] de quem é capaz de se divertir com discursos, contando histórias sobre a justiça [...]" (276e2-3:

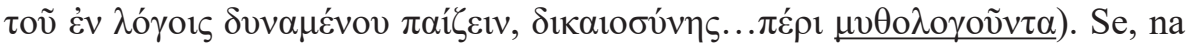
determinação dessa prática discursiva, são empregados tanto termos que se referem à modalidade oral, quanto escrita da linguagem, vê-se, de antemão, que aí não se trata de uma oposição, mas de duas formas de expressão que concorrem igualmente para caracterizar o discurso.

Além disso, a linha 276e5, que foi tomada por Szlezák (2009) como evidência do "fato decisivo de que aquele que ensina só aplica a dialética na conversação"', não contém sequer um elemento lexical que permita corroborar a dissociação radical entre o domínio da escrita em relação à prática da filosofia,

na metáfora do phármakon, podendo ser pensado tanto como um paradigma, quanto como uma imagem. Não explicitaremos aqui os passos que justificam a caracterização da escrita na ambiguidade imagem/paradigma (para o que remetemos a Fortes, 2019). No entanto, cumpre esclarecer que aqui consideramos paradigma o modelo a um tempo metodológico e explicativo de que Platão lança mão para dar conta de explicar noções mais avançadas. Como exemplos das letras tomadas como paradigma, podemos citar, fora do Fedro, duas passagens, uma na República e uma no Político. Na República (3.402a7-c9) a alusão às letras e, em particular, ao processo de aquisição da competência da leitura, parece ter a função de paradigma, na medida em que o aprendizado das letras é evocado como modelo explicativo para a compreensão do análogo processo da

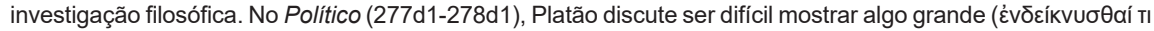

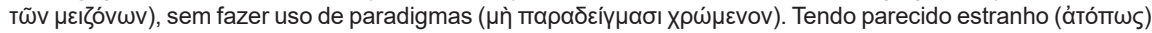

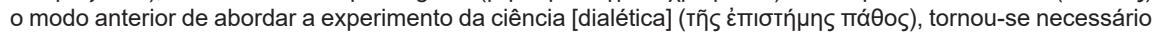

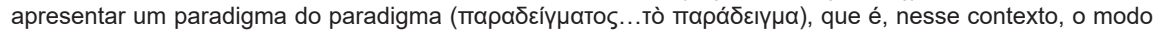
de se apropriar das letras para a leitura e escrita.

3 Cf. Szlezák (2009, p. 30, grifos nossos): "A parábola não conhece nenhuma atividade que seja ao mesmo tempo jogo e seriedade, assim como não há uma planta que corra no Jardim de Adônis e no campo ao mesmo tempo. Jogo e seriedade, escrita "mitologizante" e conversão dialética são claramente separados [...]. A alegria do escritor com seu trabalho certamente desempenhou um papel para essa denominação (cf.

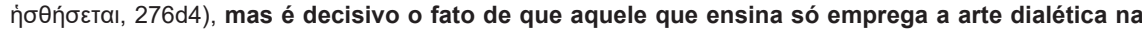
conversação (276e5)" 
tal como proposta pelo comentador. Vejamos a passagem a que Szlezák faz referência:

SÓCRATES: Pois é assim, meu caro Fedro. Mas suponho ser muito mais bela a seriedade que surge disso tudo, quando alguém empreendendo a dialética e alcançando uma alma predisposta, planta e semeia discursos com ciência - que são competentes em ajudar a si mesmos e a quem os plantou e, longe de infrutíferos, dotados de sementes da qual crescem outros discursos competentes em transmiti-la sempre imortal - fazendo feliz e à altura do possível para um ser humano quem dele se dispõe ${ }^{4}(P h d r .276 e 4-277 \mathrm{a} 4)$.

Ora, diversamente do que sugere Szlezák, a passagem acima não faz qualquer associação entre a dialética e uma suposta prática oral, menos ainda sublinha uma possível incompatibilidade entre dialética e escrita. Em vez disso, corroboram-se aspectos que já haviam sido destacados anteriormente no diálogo, que contrapunham não oralidade a escrita, mas duas modalidades do lógos - o lógos retórico, de Lísias/Fedro, e o lógos dialético, da palinódia socrática. A passagem citada acima recupera, portanto, argumentos que, desde o início do diálogo, visam a mostrar a especificidade do lógos dialético, mas por razões que não passam pela sua filiação ou não a um modo de expressão escrito. Vejamos:

1. a dialética pressupõe o encontro com uma "alma predisposta"

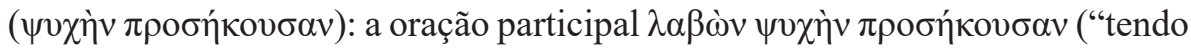
encontrado uma alma predisposta”), parece explicitar a condição pela qual é possível se realizar a dialética - é preciso que haja uma espécie de encontro entre almas, caracterizado, diríamos, por uma predisposição que se viabiliza tanto pela philía entre os dialogantes, quanto por érós que motiva o aprender, temas que já foram abordados na primeira metade do Fedro;

2. os discursos são "plantados e semeados" (

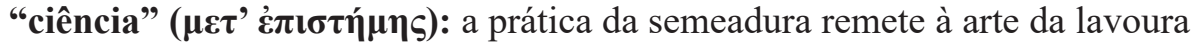
(276b6: $\tau \tilde{\eta} \gamma \varepsilon \omega \rho \gamma \iota \kappa \tilde{n} \ldots \tau \varepsilon \dot{\chi} \chi \emptyset \eta)$, o que nos permite associar a dialética àquela arte, não ao "Jardim de Adônis". Ao passo que a lavoura rende frutos no longo prazo, o "Jardim de Adônis" tem um efeito limitado a oito dias. Isso diz algo a respeito do efeito dos discursos: o lógos que se limita a entreter, ainda que seja belo quando fala de justiça, tem um efeito transitório, ao passo que a dialética, por ser produzida com "ciência", tem um efeito duradouro. A diferença entre

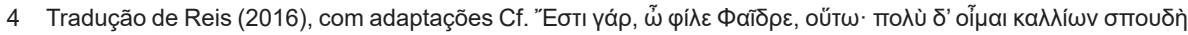

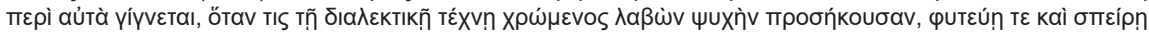

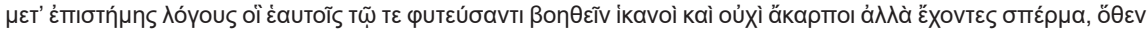

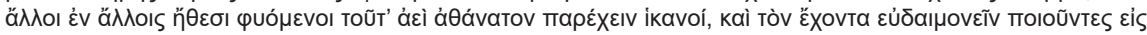

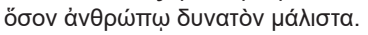


a transitoriedade e a permanência do efeito dos discursos pôde, ademais, ser verificada na prática discursiva contida no próprio Fedro: o discurso de Lísias, ainda que tenha sido considerado belo à primeira escuta, pareceu convincente a Fedro somente durante um pequeno período de tempo, o que demonstra que o efeito psicagógico da retórica seria localizado e limitado a uma primeira impressão, ao passo que o da dialética seria duradouro, visto que se constrói com base em uma "ciência"; por conseguinte, somente essa prática mostrou-se verdadeiramente psicagógica e dotada de "arte";

3. o lógos dialético é autônomo ("capaz de ajudar a si mesmo") e frutífero ("dotado de sementes das quais crescem outros discursos"): tratase aqui da oposição entre um discurso que diz sempre o mesmo, sendo incapaz de dialogar e, por isso, dependente de tutela, enfim, de um discurso "sem vida própria", e, por outro lado, um discurso vivo, que é capaz de incluir a plurivocidade e, portanto, suscitar novas discussões e novos discursos; além disso, como é dotado de sementes que germinam, esse segundo lógos caracterizase pelo movimento da vida, por ser dotado de uma "alma" ( $\dot{\varepsilon} \mu \psi v \chi o ́ v)$. Essa oposição nada diz, necessariamente, sobre uma oposição entre o oral e o escrito, haja vista que tanto a prática oral quanto a prática escrita podem ser ou não "dotados de alma". Ademais, o discurso apresentado por Fedro, da lavra de Lísias, tratava-se de um discurso oral ou escrito? A resposta não fica clara na medida em que, embora sua materialização tenha se dado, em certo instante, na redação de um texto, sua performance deu-se via oralidade ${ }^{5}$.

Esses três pontos permitem-nos, sem dúvida, retomar a distinção entre duas formas de lógos que percorrem todo o diálogo, parecendo-nos dela estar

5 Um dos pareceristas anônimos deste artigo, a quem agradecemos, sugeriu-nos um interessante contraponto com o Protágoras, no qual, especialmente na passagem que se estende de 347c3 a 348a7, revela-se uma convergência com a interpretação que oferecemos neste trabalho. Naquele diálogo, alegando possuir memória curta, Sócrates solicita que Protágoras evite o uso de discursos longos em suas falas (334d), no entanto, paradoxalmente, logo em seguida lhe responde com uma longa fala, na qual desenvolve sua interpretação em torno de um poema de Simônides, anteriormente citado por Protágoras. Terminada essa apresentação, Sócrates se volta ao seu interlocutor, propondo-lhe que retornassem, então, à discussão "séria". Fica evidente na passagem, assim como no Fedro, uma distinção entre uma interlocução "dialética" e uma expressão

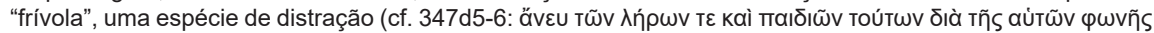

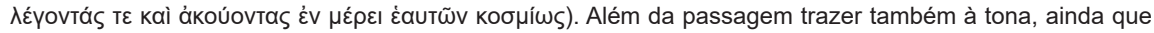
indiretamente, o tema da memória, ela deixa patente a mesma divisão (ou distinção) entre formas de expressão do discurso: um discurso que se edifica sobre outrem (no caso do Protágoras, o poema de Simônides; no caso do Fedro, o discurso de Lísias), não é capaz de fomentar o diálogo vivo que caracteriza a dialética, no qual as pessoas se responsabilizam pelos seus próprios turnos de fala. Além disso, assim como no Fedro, é possível também identificar aqui uma posição do personagem Sócrates refratária em relação aos textos

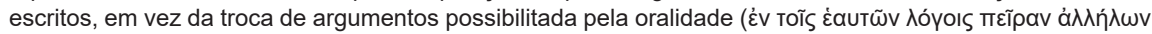

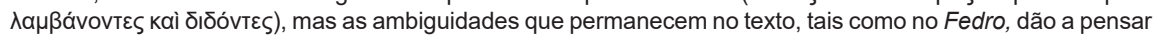
que essa relutância não seja equivalente à posição de Platão. Com efeito, assim como no Fedro, embora o texto motivante seja escrito (o poema de Simônides), a sua performance (a declamação e o comentário) são realizados oralmente. 
ausente a contraposição entre oralidade e escrita defendida por Szlezák e pelos estudiosos de Tübingen-Milão. Entretanto, restaria ainda a pergunta: por que Platão, em um primeiro momento, faz clara menção ao "escrever" ( $\gamma \rho \alpha \varphi \varepsilon i ̃ v)$ e, na segunda parte, não mais se refere explicitamente à escrita, mas a um

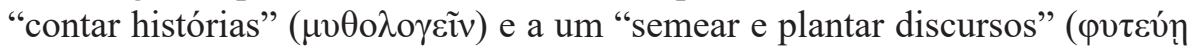

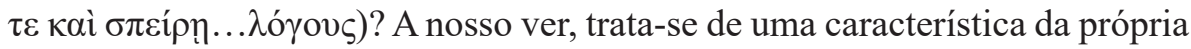
"escrita dialética" de Platão. Na passagem em questão, a escrita não é o objeto fundamental sobre o qual o debate se constrói, mas parece, antes, funcionar como um paradigma para compreender os próprios discursos e as distinções entre seus diferentes tipos. Admitindo-se que essa distinção entre escrita e oralidade funcione como um paradigma, isto é, como um recurso metodológico para a compreensão da verdadeira distinção - aquela que se opera no campo do lógos e que emerge como um efeito do diálogo Fedro como um todo, desde o primeiro encontro entre Fedro e Sócrates -, resta explicar a contraposição entre paidiá ("jogo, diversão, brincadeira") e spoudé ("atividade séria e difícil") mobilizada nessa passagem.

\section{Divertimento vs. atividade séria?}

$\mathrm{Na}$ linha dos estudiosos de Tübingen-Milão, a contraposição entre paidiá ("jogo, diversão, brincadeira") e spoudé ("atividade séria e difícil") representaria a verdadeira distinção entre a atividade do filósofo e a dos demais candidatos à filosofia: o jogo, a brincadeira, o divertimento ( $\pi \alpha \iota \delta$ '́ $)$ não faria parte da "filosofia séria" ( $\sigma \pi 0 v \delta \eta ́)$ de Platão. O “jogo" ( $\pi \alpha \iota \delta$ í́), associado inapelavelmente à escrita por esses comentadores, como explica G. Reale ${ }^{6}$, não teria lugar no âmbito da dialética. Tal como o Jardim de Adônis, a escrita e o jogo, quando comparados à oralidade da dialética, deveriam ser relegados a um segundo plano, em prol de uma atividade mais séria, da qual estariam excluídos até mesmo os diálogos escritos de Platão ${ }^{7}$. Se, como observamos

6 Cf. Reale (2004, pp. 59-60): “De fato, quem possui a ciência não pode operar com 'seriedade' fixando com a tinta e com a pena sobre rolos de papel as coisas que lhe são mais caras; justamente porque os escritos, como sabemos, não são capazes de defender-se nos seus conteúdos, nem são capazes de comunicar a verdade de modo adequado. [...] O escrito é um jogo muito belo, de dignidade muito elevada em relação a outros jogos que não valem nada. Mas a arte dialética na dimensão da oralidade é muito mais bela, e justamente nela encontra-se o empenho de seriedade [...]".

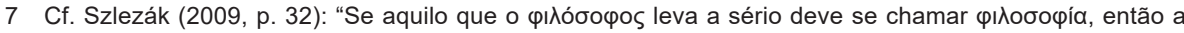
'filosofia' é, para Platão, a conversa oral, que o 'que sabe' conduz tendo em vista o 'ensinamento' de um 'aprendiz' escolhido. Portanto, de todos os $\lambda$ óyol, apenas o 'que é pronunciado no contexto do ensinamento

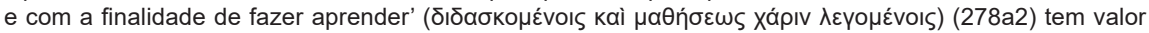
verdadeiro. Esse tipo de $\lambda$ óyo foi o único que restou de uma abrangente divisão de todos os $\lambda$ óyol: todos os escritos, metrificados ou não, não são dignos de grande seriedade. Como não há um escrito que não seja nem metrificado, nem não metrificado, é vão perguntar se os próprios diálogos de Platão, por exemplo, 
acima, os indícios que se observam na malha do texto não nos permitem contrapor oralidade a escrita, faria sentido, entretanto, como propõem esses estudiosos, reservar à filosofia o espaço exclusivo da "seriedade" ( $\sigma \pi 0 v \delta \eta ́)$, claramente separado de qualquer forma de "jogo" ( $\pi \alpha 1 \delta i \alpha ́)$ ?

Como bem anotou L. Brisson (2004, pp. 57, 58), não se deve ler a passagem, como de resto, também várias outras partes do Fedro, sem considerar a alusão indireta ao debate que Platão trava com Isócrates e Alcidamante. É sabido, por exemplo, que Alcidamante, no panfleto Sobre aqueles que escrevem

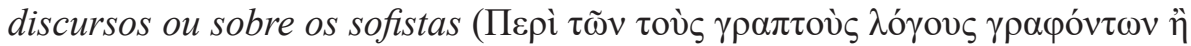
$\pi \varepsilon \rho \grave{~} \sigma o \varphi 1 \sigma \tau \tilde{\omega} \nu$ ) apresentara argumentos semelhantes aos que Platão mobiliza no Fedro, para atacar, no caso de Alcidamante, o discurso escrito de Isócrates: do ponto de vista retórico, o texto escrito seria ineficaz e inferior, seria incapaz de responder ao debate concreto e, por isso, de dar conta do tempo oportuno (каıрós), que representa o momentum do debate vivo, oral e improvisado. Assim, para Alcidamante, o texto escrito teria apenas uma finalidade pedagógica: ao emular os elementos da verdadeira improvisação, seria não mais que um “jogo" (Brisson, 2004, p. 58; Quirim, 2016, p. 80). A invectiva de Alcidamante terse-ia colocado também como uma espécie de autodefesa, talvez em resposta

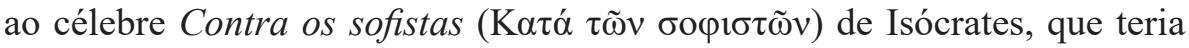
tido como alvo precisamente a obra de sofistas como Alcidamante ${ }^{8}$. Ora, o que essas alusões nos podem indicar? Em primeiro lugar, que a sombra de Isócrates já se faz sentir - embora o orador seja citado somente mais à frente, em 278e8. Para L. Brisson, Platão parece evocar argumentos de Alcidamante - nomeadamente: a associação entre escrita e pintura (275d), entre escrita e jogo (276c-d) e a oposição entre discurso inerte e vivo (276a) - certamente não para defender o mesmo ponto do sofista, i.e. a inferioridade do discurso escrito em relação ao discurso improvisado e oral, ou para condenar ipso facto o estilo de Isócrates, mas para pôr em relevo um tertium quid, a prática do lógos fundada em um tratamento metódico, profundamente implicado com a

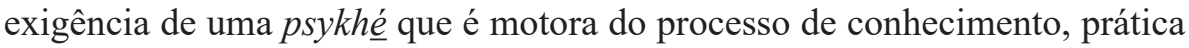
que pode ser conduzida mediante um exercício adequado da linguagem. Nas palavras de Brisson (2004):

estariam excluídos desse julgamento". Dessa citação de Szlezák, causa-nos assombro que, na linha citada como evidência do "único discurso" sobrevivente, o comentador tenha recortado a frase precisamente antes do particípio graphómenos.

8 Conforme comenta Brisson (2004, p. 58), a posição de Alcidamante seria, entretanto, uma causa perdida: o estilo de Isócrates já havia se tornado um padrão e sua maneira de escrever já se impunha em outros autores - mesmo em Platão. Tanto é assim, que Aristóteles, na Retórica (III, 3), tomará a posição ao lado de Isócrates, contra Alcidamante. 
Ele [Platão] desloca o centro de gravidade de sua crítica à escrita, que em Alcidamante e mesmo em Isócrates envolvia a atenção ao momento oportuno (kairós). Portanto, aquela capacidade de se adaptar à ocasião e de tirar proveito da conjuntura cede lugar à necessidade de discernimento metódico dos tipos de almas e dos tipos de discurso, baseado na prática da dialética (Fedro 271c-277a, 277b-c) $)^{9}$ (BRISSON, 2004, p. 59).

Portanto, se a leitura que Brisson (2004) e Quirim (2016) fazem da obra de Alcidamante e Isócrates estão corretas, é possível afirmar que Platão, insinuando-se no debate realizado por esses dois autores, reapresentando parcialmente os argumentos do primeiro, Platão desloca a questão para outro terreno: aproveita-se do debate em curso sobre a escrita, mas não com a intenção de marcar uma posição (seja contra ela, cf. Alcidamante, ou a seu favor, cf. Isócrates), mas para erigi-la em paradigma de uma discussão maior, i.e. a de determinar que tipo de lógos é adequado ao processo de conhecer; processo que, conforme vimos, Platão não revela indícios de que dependa do aproveitamento de uma conjuntura, de um tempo oportuno - do kairós - mas de uma propensão psíquica, privativa dos humanos, de se porem em marcha, em uma espécie de movimento de rememoração. Ademais, pensasse Platão tal como Alcidamante - que teria se contraposto aos discursos escritos em favor de uma oralidade improvisada (Brisson, 2004) -, não teria ele francamente representado, como vemos na Apologia, o paradoxo dessa posição? De fato, o improviso oral de Sócrates representado por Platão naquela ocasião mostrarase francamente ineficaz na defesa de seu ponto de vista, não fora propriamente persuasivo ou psicagógico, como se supõe de um discurso filosófico nos termos do Fedro ${ }^{10}$.

Além disso, a imagem do "Jardim de Adônis" de que Platão lança mão, conforme indicaremos no próximo item, faz alusão a uma forma de cultivo temporária, opondo-se à verdadeira agricultura, cujas safras, se espera, são duradouras. A atenção retórica ao kairós de Alcidamante poderia ser associado a essa forma de jardinagem, ao passo que os interesses de Platão em relação à dialética guarda a pretensão de produzir frutos de longa duração. Assim, é possível admitirmos que também haja aí uma discordância crucial entre Platão

9 Cf. "Mais il déplace le centre de gravité de sa critique de l'écriture, qui, chez Alcidamas et même chez Isocrate, implique une attention au moment oportun (kairós) et donc la capacité à s'adapter à l'ocasion et à profiter de la conjoncture, cède la place à la nécessité d'un discernement méthodique, fondé sur la pratique de la dialectique, des genres d'âmes et des genres de discours (Phèdre 271c-277a, 277b-c)".

10 Mesmo em outros diálogos, o insucesso das discussões entre Sócrates e os sofistas mostram que simplesmente a oralidade improvisada não é o suficiente para a dialética, como, por exemplo, em diversas ocasiões em que Sócrates abre mão de simplesmente perguntar - como discurso contido na parte final do Górgias - e, mesmo assim, não logra persuadir seus interlocutores. A exigência da dialética, portanto, vai muito além da discussão oral e improvisada. 
e Alcidamante: embora ambos vejam a interlocução oral como dotada de alma (है $\mu \psi v \chi 0 v)$, a compreensão de ambos em relação a isso diverge. Para Platão, um discurso dotado de alma é aquele que permanece, é duradouro e pode sempre responder por si mesmo; para Alcidamante, tal discurso é como o jardim de Adônis, depende de habilidades improvisatórias e tem um efeito limitado no tempo ${ }^{11}$.

Assim sendo, admitir que corresponderia à posição de Platão o argumento de Alcidamante de que a escrita seria um jogo de menor importância, não somente implica ignorar a sutileza do debate posto no próprio Fedro - e as diferentes vozes que se podem ouvir nas entrelinhas -, mas também desconsiderar as relações entre essa passagem e as demais partes do diálogo, e, em particular, toda a discussão precedente sobre a psykhagogía, sobre a psykhé e sobre a anámnesis.

Concordamos com R. Burger (1980, p. 100), em vez disso, com o fato de que o Fedro exige do leitor a quebra de uma ilusão: aquela que consistia em admitir que Platão, embora representasse Sócrates como seu personagem principal no Fedro, estivesse apresentando ipsis verbis a sua própria posição através das falas de seu mestre. Embora a posição de Sócrates - o personagem, ao menos - possa de fato estar mais explícita no texto e ser veículo mesmo de certa reserva à escrita, como vemos no mito de Theuth; Platão, o "personagem invisível" nessa cena dramática, não a teria necessariamente assumido para si, quando não seria o caso mesmo de tê-la deliberadamente subvertido ${ }^{12}$. Assim, o contraste entre o caráter lúdico do Jardim de Adônis e a seriedade do plantio das sementes no solo e estação adequados, que aparece na fala de Sócrates como uma primeira oposição entre os jogos da escrita e uma prática mais séria da dialética (talvez oral, para Sócrates), cederia lugar para uma outra e mais profunda distinção, agora de interesse de $\mathrm{Platão}^{13}$, que repousaria, para Burger,

11 Devo o comentário contido nesse parágrafo à excelente contribuição oferecida por um dos pareceristas anônimos, a quem agradeço.

12 R. Burger (1980) argumenta no sentido de que, do mesmo modo que a distância entre o que poderíamos considerar como método filosófico de Sócrates e o pensamento filosófico maduro de Platão emerge sutilmente na estratégia platônica de deliberadamente se tornar invisível nas imitações dramáticas dos diálogos; no diálogo entre Theuth e Thamos no Fedro, e nas passagens que o seguem, o contraste entre Sócrates - o filósofo que, de fato, nada escreveu - e Platão - o filósofo que, de fato, levou o gênero escrito do diálogo a complexidade antes não conhecida - estaria representado na contraposição entre uma aparente condenação da escrita por Sócrates e a sutil defesa de seu potencial filosófico por Platão.

13 A necessidade de reconhecer uma distinção entre o que se diz nas falas de Sócrates e o pensamento de Platão - a que os comentadores da Escola de Tübingen-Milão não atentam - é também reconhecida por G. Ferrari (1990, p. 213) que, embora não subscreva a posição de Burger (1980), por ele mesmo rebatida, afirma, por exemplo, que: "Certainly, when we take these points of presentation into account we see that an extreme interpretation of Socrates' words, which would strictly confine the effects he describes according to mechanical boundaries of format, is not a plausible reading of Plato's intent". 
na "oposição entre um lógos ilegítimo, sem raízes, que é como uma pintura silenciosa, e o lógos dialético, falado ou escrito, cujas raízes são plantadas na alma do aprendiz" (Burger, 1980, p. 121) ${ }^{14}$.

Nesse sentido, a manipulação que Platão faz dos diferentes recursos na sua escrita - o uso das imagens, das alegorias, o emprego de símiles, a presença de polifonia, as alusões, a polissemia etc.- se afiguraria também como uma espécie de jogo da linguagem a serviço da filosofia, em prol de uma escrita dialética. A escrita do próprio diálogo contém, nela própria, portanto, os elementos desse "jogo de linguagem", ainda que tenha a pretensão de ser dialética, nos termos de Platão. Sendo assim, como é possível sustentar a incompatibilidade entre paidiá e spoudé, posição defendida por Szlezák (2009) e Reale (2004)?

Além disso, para se defender a tese de que exista nesta passagem uma incompatibilidade entre jogo, ou divertimento $(\pi \alpha 1 \delta$ เó $)$ e a seriedade da dialética ( $\sigma \pi 0 v \delta \eta ́)$, seria preciso, retomando o paradigma apresentado, admitir que fosse também inconciliável a atividade do lavrador que produz o "Jardim de Adônis" e aquele que cultiva o campo, elementos evocados na passagem. Ora, no trecho em questão, Sócrates formula hipoteticamente a possibilidade de o lavrador sério cultivar tais jardins, não havendo aí, necessariamente, uma interdição. $\mathrm{O}$ que parece ficar claro é que, na hipótese de o lavrador cultivar os Jardins de Adônis, ele o deveria fazer como "uma brincadeira", não levando tal atividade a sério. Apenas o plantio adequado das sementes, em se respeitando a época propícia e o tempo de cultivo correto, é que mereceria sua maior atenção e "seriedade". Não se trata, portanto, de uma antinomia, mas de um elaborado exercício de divisão e reunião, procedimento que, conforme sabemos no próprio Fedro, é intrínseco à própria definição da dialética (265e1-266c5; 249b6-c1).

\section{De volta ao "Jardim de Adônis"}

Como consequência do que vimos na seção anterior, ao apresentar a imagem do "Jardim de Adônis", Platão parece colocar as duas atitudes - o jogo e a seriedade - em uma relação mais complexa, não propriamente de oposição. Trata-se, antes de uma divisão (ou, se preferirmos, de uma distinção), procedimento próprio do método advogado por Platão neste diálogo.

Contudo, Platão não parece endossar propriamente a prática do cultivo do "Jardim de Adônis" e, nesse sentido, poderíamos perguntar: não haveria aí uma assimetria de valor que, resultaria, de modo prático, em uma espécie de oposição 
atenuada entre ambas as práticas, resultando na valorização e enaltecimento de uma (a atividade séria, a agricultura) e na desvalorização e depreciação de outra (o jogo, o "Jardim de Adônis")? Se levarmos em conta o significado cultural dos jardins de Adônis, parece-nos que devemos também rejeitar essa hipótese. Com efeito, conforme explica Parker (2005, p. 283), os pequenos jardins plantados em cestas ou em fragmentos de vasos de terracota destinavam-se a uso ritual nas festas de Adônis, um festival em que as mulheres lamentavam a morte do personagem mítico em questão. Esses artefatos simbolizariam a morte prematura do jovem que, segundo a mitologia, teria despertado o amor de Afrodite e, de acordo com diferentes narrativas, teria sido morto por um javali selvagem, enquanto caçava na floresta, talvez por vingança de Ártemis (Howatson, 2005, p. 6). Ora, por que Sócrates, já anteriormente alertado pelo seu daímon da impiedade em que incorrera havia pouco contra Éros (Phdr. 242b8-d2), se colocaria novamente contra uma divindade, posicionando-se contra um ritual que, ademais, celebrava justamente o éros? Não nos parece plausível, portanto, que nessa passagem Platão proponha uma visão negativa/ depreciativa dessa prática, sem incorrer em uma flagrante contradição. Assim sendo, o jogo - o cultivo do Jardim de Adônis - não somente mereceria ser respeitado, dentro de sua dignidade ritualística, como poderia também ser o símbolo da relação entre homens e deuses, tendo Éros como elemento comum, tema que ademais ecoa e unifica a discussão precedente do diálogo.

Do mesmo modo, se nos estendemos à imagem do jardim das letras

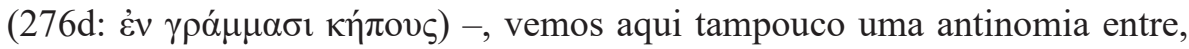

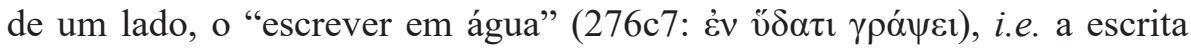
por diversão ou brincadeira $(\pi \alpha \imath \delta \imath \alpha ́)$ - ainda que ela pudesse render frutos muito belos, como os discursos sobre a justiça - e, por outro lado, a dialética,

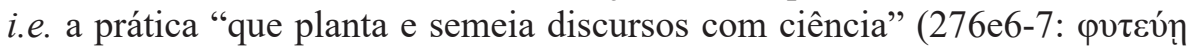

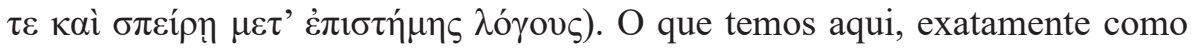
no caso da lavoura, é uma vez mais a apresentação do exercício dialético da divisão e reunião, exatamente como testemunhamos na contraposição dos dois discursos proferidos por Sócrates na primeira metade do diálogo. Ou seja, o conhecimento - aqui, no caso, da "bela escrita" - não emerge da proposição particular contida em cada um dos membros dessa divisão, mas assoma como o efeito do próprio exercício de dividir e reunir. Assim sendo, a escrita dialética não emerge na passagem senão como o resultado desse esforço: a despeito das inegáveis limitações da linguagem, e da escrita, em particular, é como se Platão nos convidasse a nos engajar nessa prática de divisão e reunião, um trabalho sério e difícil ( $\sigma \pi \circ v \delta \eta ́)$, mas cuja recompensa é de uma beleza superior ( $\kappa \alpha \lambda \lambda i \omega v)$ : compreender a própria dialética e, portanto, tornar-se apto 
a ser filósofo. Assim como a noção de Éros não era possível de ser apreendida senão se o leitor se engajasse no exercício de divisão e reunião que se propõe para a interpretação de ambos os discursos de Sócrates na primeira parte do diálogo, efeito análogo se supõe dessa divisão agora posta para compreender os efeitos da linguagem para o discurso belo e filosófico. Seria filosoficamente inadequado aderir apressadamente a qualquer um dos lados dessa disputa e reduzir, como vimos, a posição de Platão a uma das posições já postas sobre o tema na querela entre Alcidamante e Isócrates.

Em outras palavras, como bem mostrou A. Cotton (2014, p. 4 et seq.), esse constante movimento dialético, que podemos identificar na malha do texto de Platão desde que não o reduzamos a signos que transmitem uma doutrina fechada, é paradigmático do próprio filosofar. Por intermédio desse paradigma, como sustenta a estudiosa, os diálogos de Platão "nos encorajam a nos engajarmos neles por nós mesmos, e apontam adiante para um filosofar ativo, além dos limites do texto"15. Concordamos com Cotton $(2014$, p. 7) que "parece claro que a passagem foi projetada para nos parecer perturbadora e desencadear em nós um processo de reflexão sobre as questões que ela levanta." 16

\section{Ressonâncias no diálogo: um lógos à altura do humano}

No final da passagem que discutimos acima (277a9-b3), a questão levantada por em $258 \mathrm{~d} 7$ e reposta em $269 \mathrm{c} 9$-d 1 - em que consiste escrever um discurso com arte? - pareceu a Sócrates finalmente ter sido respondida, como se depreende da passagem abaixo. Após anunciar que lhes faltara ainda considerar uma questão, Sócrates assim enuncia:

SÓCRATES: Aquilo de que tratávamos e, querendo examinar, nos trouxe em direção a isto: como passar em revista a reprimenda a Lísias quanto à escrita e aos próprios discursos - que podem ser escritos com arte ou sem arte. E parece-me então ter ficado suficientemente claro em que consiste ou não ter arte.

FEDRO: De fato, parece. Mas faz com que eu me lembre mais uma vez ${ }^{17}(P h d r$. 277a9-b4).

$15 \mathrm{Cf}$. "they encourage us to engage in it for ourselves, pointing towards further active philosophizing beyond the confines of the text".

16 Cf. "it seems clear that the passage is designed to strike us as troubling, and to trigger in us a process of reflection about the issues it raises [...]".

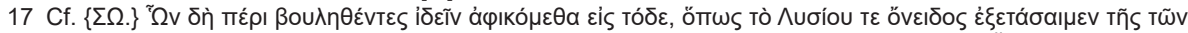

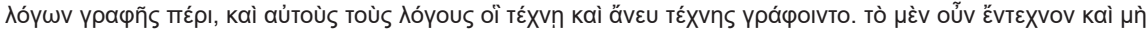

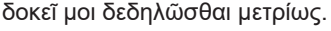

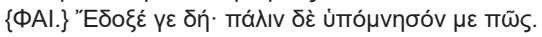


Se Sócrates, nessa passagem, afirma possuir a resposta para a questão formulada previamente, talvez ela ainda não estivesse clara para os demais interlocutores de Platão - quiçá nem mesmo para Fedro que, embora anuísse com Sócrates no passo citado, lhe pedia uma nova explicação, que lhe "ajudasse a se lembrar" (vं ó $\mu v \eta \sigma o ́ v)$. Por que Sócrates aparenta já compreender a questão, e Fedro, embora concorde com ele, ainda requer nova explicação? Para a questão posta, a que conclusão chegaram os personagens?

$\mathrm{Na}$ argumentação anterior, deparamo-nos com a oposição entre uma forma de escrita (e de lógos) caracterizada por ser dependente, desprovida de vida e incapaz de oferecer respostas diferentes para perguntas variadas e, por outro lado, aquela outra forma que, possuindo ciência, seria produtora de novos discursos, e então poderia ser caracterizada por possuir autonomia e mobilidade - configurando, assim, o lógos da dialética. Imediatamente antes da passagem que nos interessa neste artigo, Sócrates encerrara a caracterização dessa segunda forma de escrita (e de lógos), afirmando que somente esta seria capaz de "tornar feliz e à altura do possível" quem dela se dispusesse (277a3-4:

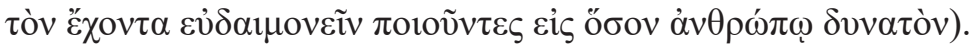

Esse breve adendo final na fala de Sócrates acentuava a potência de a

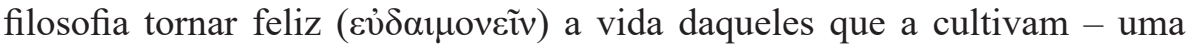
preocupação, diga-se de passagem, jamais ausente do fazer filosófico no mundo antigo ${ }^{18}$. Ao mesmo tempo, sublinhava o caráter relativo dessa potência, isto é, o cultivo da dialética conduz a um estado de felicidade limitado ao "quanto é

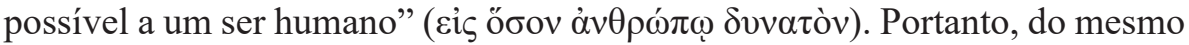
modo que competiria aos mortais o engajar-se na busca filosófica, o resultado

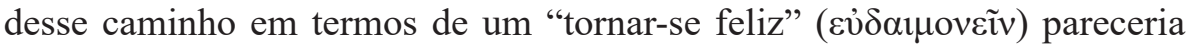
conformar-se à condição humana. Isso parece remeter àquela distinção filosófica que subjaz a reflexão presente em todo o diálogo: a distinção entre o estatuto da sophía - divina, "hiperurânia", ligada a uma visão plena e absoluta das Formas, sem intermediários - e da philo-sophía - uma atividade humana, um movimento psíquico de rememoração (àvó $\mu v \eta \sigma ı)$ ), para o qual se tornam necessários expedientes intermediários, tais como um método - a dialética - e paradigmas - como a escrita, essa forma de oferecer uma "lembrança" (نं ó $\mu \nu \eta \sigma ı)$. De fato, como Sócrates afirma mais à frente, chamar de sábio (боழós) quem maneja com excelência o lógos "parece ser algo grande demais,

18 De fato, conforme defende P. Hadot (2014), a filosofia antiga é, sobretudo, “um modo de vida”, que pressupõe uma opção existencial, a busca por uma vida comunitária e o desenvolvimento de um discurso teórico a partir dessa visão de mundo, que tem em vista à sabedoria (бọía) e, como consequência dela, a felicidade

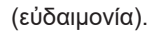




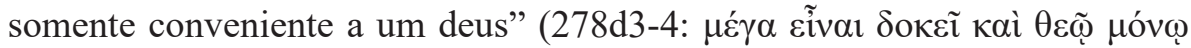
$\pi \rho \varepsilon ́ \pi \varepsilon t v)$.

Na prática, em que consistiria a atividade filosófica à altura (ou no limite) do gênero humano? Em que consistiria produzir um discurso "com arte"? De fato, uma condição para esse tipo de lógos fora também oferecida em 273d8-e4:

se alguém não enumerar as naturezas dos que vão ouvi-lo, se não for capaz de dividir os seres por formas e compreender com uma única ideia de acordo com cada um deles, jamais será hábil em discursos à altura do possível ao ser humano ${ }^{19}(P h d r$. 273d8-e4, grifos nossos).

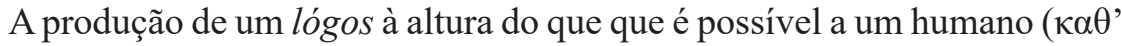

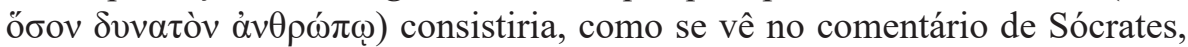
no procedimento de dividir um objeto de acordo com as formas ( $\kappa \alpha \tau^{\prime} \varepsilon^{\prime} \delta \eta \eta \tau$ $\delta ı \iota \iota \varepsilon i ̃ \sigma \theta \alpha \imath)$ e reuni-lo em uma única ideia, resguardando-se a natureza de cada

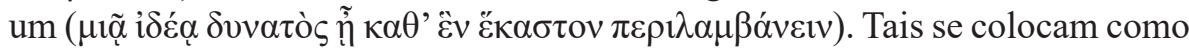
condições - explícitas pelo período hipotético introduzido pela conjunção દ̇av para alguém lograr se tornar um tekhnikós lógon, i.e. alguém capaz de produzir um discurso verdadeiramente artístico. Ora, conforme vimos, tais operações descrevem a dialética conforme definida no $\mathrm{Fedro}^{20}$ e as operações de divisão e reunião descritas na passagem implica distinguir as naturezas daqueles que

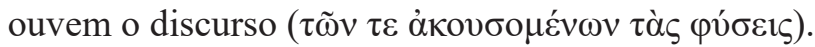

Já estaria claro a Sócrates, portanto, que o discurso artístico ( $\tau \varepsilon \chi v i k o ̀ \varsigma$ $\lambda$ ó $0 \varsigma$ ) deveria levar em conta aqueles que o ouvem. Assim, ele não poderia prescindir de uma flexibilidade e mobilidade tais, de modo a fazer jus às diferentes psykhai daqueles que o recebem. Ou seja, se é verdade que há diferentes naturezas de ouvintes e se é preciso distingui-las, seria igualmente forçoso que o lógos a eles direcionado desse conta dessas diversas formas de recepção. Compreende-se, então, por que um discurso que, como uma pintura, se limitasse somente a responder o mesmo - e não a dialogar - só poderia estar aquém dessa exigência fundamental. Fica também claro como associar

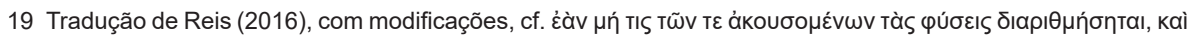

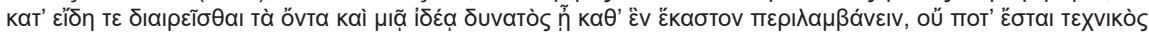

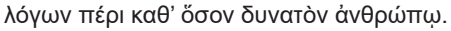

20 "Reunir em uma única ideia coisas dispersas aqui e ali, abarcando-as numa visão de conjunto, a fim de tornar evidente, definindo cada coisa, aquilo em que cada caso pretende ensinar. Tal como agora mesmo a respeito de Éros - quando definido o que é -, esteja bem ou mal enunciado, o discurso teve como dizer graças a isso

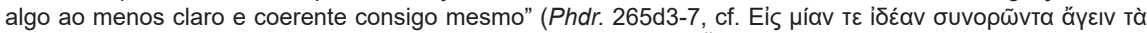

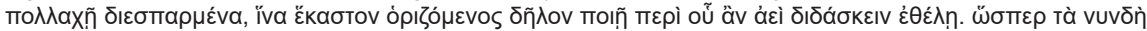

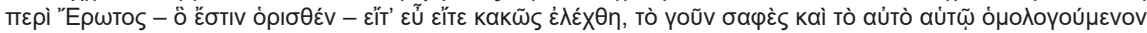

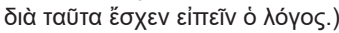


essa forma de discurso simplesmente a um modo de expressão oral parece ser insuficiente para caracterizá-lo, pelas palavras ouvidas se pode, igualmente, gerar um discurso que não leva em conta as psychai dos interlocutores; tratandose, em suma, de um discurso oral, porém não dialético ${ }^{21}$.

Além disso, tal exigência implicaria tanto um modo particular de expressão - uma modalidade específica de performance dos lógoi, de modo a serem "frutíferos", capazes de produzirem outros discursos (Phdr. 276e4-277a4) -, quanto o conhecimento a ele associado - um conhecimento pertinente à natureza da alma humana, para o que a palinódia e a alegoria da alma como biga alada antes apresentadas revelam-se novamente fecundas para essa reflexão ${ }^{22}$.

\section{Conclusão}

Oferecemos neste artigo uma interpretação da passagem entre $276 \mathrm{~b} 1 \mathrm{e}$ 277 b3 do diálogo Fedro, de Platão. Ao analisarmos as imagens do "Jardim de Adônis" e do "Jardim das Letras", constatamos não ser possível subscrever

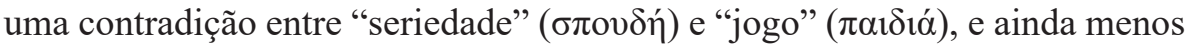
concordar com a associação entre quaisquer desses termos e as ideias de oralidade e escrita. Platão mobiliza o tema da escrita, na parte final do diálogo, como um paradigma - aqui entendido como um recurso metodológico - para colocar em jogo o tema que percorre o Fedro como um todo: a determinação do lógos filosófico, i.e. da dialética. Se esta fora definida como um movimento de divisão e reunião, impõe-se-nos, também nessa passagem, compreender como essa contraposição entre oralidade e escrita, entre jogo e atividade séria não são propriamente antinomias que opõem lados excludentes, mas contraposições discursivas próprias do jogo dialético (divisões, diaíresis), a partir das quais é preciso buscar uma correspondente reunião (synagogée). Por essa razão, para uma leitura filosófica - dialética - da passagem, cumpre não aderir imediatamente a qualquer uma das posições, mas buscar uma leitura que

21 No entanto, poderíamos aqui nos questionar se o discurso oral, em qualquer medida, seria mais adequado à espontaneidade do discurso dialético, que precisaria de agilidade para "defender a si mesmo". Em tese, talvez possamos admitir essa possibilidade. Contudo, acrescentaria que essa constatação é contrabalançada pelo inegável esforço criativo de Platão para forjar uma escrita dialética, em que, mediante recursos literários variados, análoga agilidade seria possível, assim como ela seria portadora, talvez, de igualmente fecunda capacidade de responder a questões colocadas. Além disso, conforme também nos indicou um dos pareceristas, a ambiguidade do verbo grápho ("anotar", mas também "pintar"), parece confundir as fronteiras entre a crítica à pintura e à própria escrita. Traçar os limites entre as duas acepções do termo no diálogo, se possível, demandaria, contudo, um esforço analítico que transcende o escopo deste artigo.

22 Fato que desafia a perplexidade dos comentadores que indicam problemas quanto à unidade do Fedro (Nichols Jr., 2016). Parece-nos bastante claro que o núcleo ontológico da "palinódia" descreve o tipo de ciência fundamental que se requer dos que sabem manejar os discursos com arte. Assim, as duas partes do diálogo não se podem dissociar. 
não está posta explicitamente por escrito no diálogo de Platão, mas que decorre de um esforço de interpretação filosófica.

Além disso, a redução do debate em questão a uma mera tomada de partido contra a escrita, parece-nos incompatível com a polissemia que emerge do próprio diálogo de Platão, que põe em cena não somente posições divergentes - Fedro/Sócrates; Theuth/Thamos; mas evoca intertextos de um debate vivo sobre escrita e filosofia à época de Platão, bem como representa posições que se contradizem dentro do próprio diálogo, como a de Sócrates, sobre a importância da escrita, ou a de Fedro, sobre o valor do discurso de Lísias. Particularmente, a imagem parece recuperar argumentos do debate entre Isócrates e Alcidamante sobre a escrita, como são analisados por Brisson (2004) e Quirim (2016). Ao evocar os argumentos de Alcidamante - a associação entre escrita e pintura (275d), entre escrita e jogo (276c-d) e a oposição entre discurso inerte e vivo (276a) - Platão põe em relevo a prática do lógos fundada em um tratamento metódico, coerente com a exigência de uma psykhé que é o motor do processo de conhecimento e que também é conduzida mediante um adequado exercício da linguagem. A passagem pressupõe, portanto, todo o desenvolvimento que se apresentara na primeira parte do diálogo, e, particularmente, no núcleo teórico contido na palinódia socrática. Ou seja, Platão parecia tomar o debate histórico sobre a escrita como o paradigma para aquela discussão mais ampla, que implicava determinar que tipo de lógos seria adequado ao processo de conhecer - aquele que seria capaz de conhecer a alma e se adaptar aos seus ouvintes, em um processo associado à propensão psíquica, própria aos humanos, de se porem em marcha, pela rememoração, o que está à altura dos seres humanos, porque é característico de sua vocação "filosófica".

\section{Referências}

ALCIDAMANTE. “Testimonios y Fragmentos”. Tradução para o espanhol de J. L. López Cruces, Javier Campos Daroca e M. A. Márquez Guerrero. Madrid: Ed. Gredos, 2005. BRISSON, L. "Introduction". In: PLATÃO, 2004, pp. 13-68.

BURGER, R. "Plato's Phaedrus. A defense of a philosophic art of writing". Alabama: The University of Alabama Press, 1980.

COTTON, A. K. "Platonic dialogue and the education of the reader". Oxford: Oxford University Press, 2014.

FERRARI, G. R. F. “Listening to cicadas. A study of Plato's Phaedrus". Cambridge: Cambridge University Press, 1990.

FORTES, F. S. "A dialética e as letras: imagens e paradigmas do pensar no Fedro de Platão". Tese de Doutorado em Filosofia. Belo Horizonte: UFMG, 2019. 
HADOT, P. "O que é a filosofia antiga?" Tradução para o português de Dion Davi Macedo. São Paulo: Loyola, 2014.

HÖSLE, V. "Interpretar Platão". Tradução para o português de Antônio Celiomar Pinto de Lima. São Paulo: Loyola, 2008.

HOWATSON, M. C. "The Oxford companion to Classical Literature". Oxford: OUP, 2005.

ISÓCRATES. "Discursos I". Tradução para o espanhol de Juan Manuel Guzmán Hermida. Madrid: Gredos, 1979.

NICHOLS Jr., J. H. “Introdução ao Fedro”. In: PLATÃO, 2016, pp. 37-72.

PARKER, R. "Polytheism and society at Athens". Oxford: Oxford University Press, 2005. PERINE, M. "Platão não estava doente". São Paulo: Loyola, 2014.

PLATÃO. "Fedro". Tradução para o português, introdução e notas de Maria Cecília Gomes dos Reis. São Paulo: Companhia das Letras, 2016.

. "Phaedrus". Editado por Harvey Yunis. Cambridge Greek and Latin Classics. Cambridge: Cambridge University Press, 2014.

QUIRIM, D. "O kairós da escrita e do discurso improvisado em Alcidamante e Isócrates". Revista Ética e Filosofia Política, Juiz de Fora, v. 19, v. 2, pp. 78-93, 2016. [Online] Disponível em http://www.ufjf.br/eticaefilosofia/files/2009/08/19_2_quirim.pdf. (Acessado em 02 de março de 2021).

REALE, G. (1991). "Para uma nova interpretação de Platão". Tradução para o português de Marcelo Perine. 2. ed. São Paulo: Loyola, 2004.

SZLEZÁK, T. (1985). "Platão e a escritura da Filosofia. Análise de estrutura dos diálogos da juventude e da maturidade à luz de um novo paradigma hermenêutico". Tradução para o português de Milton Camargo. Loyola, 2009.

TRABATTONI, F. "Oralidade e escrita em Platão". Tradução para o português de Fernando Rey Puente e Roberto Bolzani Filho. São Paulo: Discurso Editorial, 2003. . "Scrivere nell'anima. Verità, dialettica e persuasione in Platone". Firenze: La nuova Italia Editrice, 1993. 